\title{
Crisis multidimensional y sostenibilidad de la vida
}

\author{
Amaia PÉrez Orozco \\ Economista feminista e investigadora independiente \\ amaiaorozco@gmail.com
}

Recibido: 03.12.2011

Aceptado: 15.01.2012

\section{RESUMEN}

En el presente texto se propone una mirada a la crisis desde la sostenibilidad de la vida como alternativa a la perspectiva hegemónica focalizada en los mercados. Se argumenta que la crisis es multidimensional y acumulada, civilizatoria, y que precede al estallido financiero. Se analizan sus consecuencias en términos de los procesos vitales y se propone abrir dos debates para afrontarla: qué entender por vida que merezca la pena ser vivida y cómo construir una responsabilidad colectiva en la generación de sus condiciones de posibilidad. Finalmente, se argumenta que es necesario devolver la economía al terreno de la discusión política.

Palabras clave: crisis, sostenibilidad de la vida, conflicto capital-vida, capitalismo heteropatriarcal.

\section{Multidimensional crisis and life sustainability}

\begin{abstract}
This text makes an argument for putting at the center sustainability of life when understanding the crisis, therefore challenging the hegemony of market-oriented perspectives. The crisis is characterized as a multidimensional and accumulated process preceding the financial meltdown. Its consequences in terms of life dynamics are explored. It is argued that there is an urgent need to open up two debates: what is a live that is worthwhile living, and how a collective responsibility in setting its conditions of possibility could be achieved. Finally the case is made for bringing economic debates back into the political realm.
\end{abstract}

Key words: crisis, sustainability of life, capital-life conflict, hetero-patriarchal capitalism.

\section{INTRODUCCIÓN}

Estamos viviendo un cambio imparable que no podemos dejar al arbitrio del libre mercado. Para afrontarlo bajo criterios de justicia, es urgente romper con las miradas habituales de la crisis, tanto con la hegemonía de la ortodoxia, secuestrada por los mercados financieros, como con aquella mirada frecuente en la heterodoxia que se centra en la “economía real”. La economía feminista, que es feminista en tanto en cuanto contiene una “pretensión de subversión”1, puede jugar un papel

\footnotetext{
1 Expresión tomada de Sara Lafuente Funes.
} 
clave en este sentido. Este texto pretende abrir preguntas desde una apuesta analítica y política concreta: poner la sostenibilidad de la vida en el centro. No busca ofrecer soluciones, sino recoger debates que hemos ido teniendo desde la economía feminista y que entran en diálogo con otras perspectivas críticas. Es preciso señalar que se localiza en el contexto concreto del estado español, por lo que muchos de los ejemplos o afirmaciones responden a esa realidad, especialmente el apartado 7. Sin embargo, tenemos la esperanza de que esto no impida una discusión más amplia con miradas propias de otros lugares.

La estructura del texto es la siguiente: Para entender la crisis civilizatoria son imprescindibles miradas críticas que se rebelen contra los mercados; una de ellas es la mirada desde la sostenibilidad de la vida (apartado 2). Este artículo ahonda en qué implica esta mirada y cómo se lee la crisis desde ella: en qué consiste la crisis (apartado 3), cómo se produce el ajuste y cuáles son las consecuencias que está teniendo (apartado 4). Ante esta crisis civilizatoria, la contrapropuesta no puede ser recuperar la "producción" (apartado 5), sino abrir dos debates: qué es una vida que merece la pena ser vivida y cómo colectivizar la responsabilidad de garantizar sus condiciones de posibilidad (apartado 6). Estos debates han de ser radicalmente democráticos; en un contexto donde no existen estructuras de democracia real, el $15 \mathrm{~m}$ contiene la potencia necesaria para abrirlos (apartado 7).

\section{DESDE DÓNDE (NO) MIRAR LA CRISIS}

La mirada hegemónica que se nos impone para pensar la crisis posiciona en el centro de atención a los mercados financieros, sus procesos, lógica y necesidades; entendiendo que el conjunto social es unilateralmente dependiente de su buen funcionamiento. Esta mirada se caracteriza por su obscurantismo, respaldado por la complejidad del aparataje financiero. Solo los expertos pueden entender qué ocurre y así dilucidar la respuesta de política económica adecuada para restablecer el equilibrio mercantil y, de manera derivada, el bienestar. A esta mirada podemos calificarla como una "teocracia mercantil"2, porque impone las necesidades del proceso de valorización del capital financiero como una especie de "designio divino" inescapable (esto es, que ha de acatarse al margen de la voluntad humana) e inescrutable (los tecnócratas se convierten en sacerdotes mediadores entre la divinidad y el vulgo). Desde el feminismo afirmamos que lejos de ser un discurso tecnicista neutro, la "teocracia mercantil" es una mirada androcéntrica que resulta sumamente peligrosa, toda vez que impone como única visión verdadera aquella que sostiene el statu quo y relega el bienestar del conjunto social a una posición

2 Dado que el chantaje de la deuda es uno de los mecanismos principales para imponer medidas que benefician al capital, hay quienes prefieren hablar de una deudocracia. Para ampliar, véase, entre otros: QUIÉN DEBE A QUIÉN (2011), así como los videos del encuentro "Viviendo en deudocracia" http://www.quiendebeaquien.org/spip.php?rubrique131. 
periférica y subalterna. Dicho de otra forma, desde la economía feminista el capitalismo financiero lejos de ser naturalizado o, peor, divinizado, es cuestionado.

Hay otra mirada, con fuerte presencia entre la heterodoxia, que cae en lo que podríamos denominar un "estrabismo productivista" (Picchio, 2009). Esta perspectiva parte de una dura crítica a la subordinación de la "economía real” al capital financiero. Su foco de atención es el proceso de "producción” y los elementos asociados al mismo: trabajo (remunerado), salario, consumo, demanda agregada, inversión, gasto público, etc. Esta mirada sigue anclada en los mercados. El estrabismo productivista tiene una vertiente feminista, que pone el acento en la presencia diferencial de mujeres y hombres en los mercados y, sobre todo, en el mercado laboral $^{3}$. Desde aquí, se insiste en los efectos de la crisis sobre el empleo y se reitera que, si bien en un comienzo pudo golpear más duramente a los hombres, la dinámica posterior así como el peor punto de partida hacen que podamos afirmar sin género de dudas que la crisis tiene un mayor impacto sobre las mujeres. El leit motif de este "feminismo productivista" es demostrar que, al final, siempre "las mujeres, peor"4.

En este artículo intentamos dar una alternativa a esas dos opciones, desde la convicción de que estamos afrontando una crisis sistémica y civilizatoria, en la que lo que necesitamos cuestionar es el conjunto del "proyecto modernizador", la idea misma de desarrollo, progreso y crecimiento ${ }^{5}$. Frente a la existencia de un discurso hegemónico que legitima y fomenta un sistema que es insostenible e injusto, es urgente la confluencia y el diálogo de miradas críticas que arranquen desde fuera de los mercados. Aquí se sitúan propuestas de corte más activista, como el decrecimiento desde el ecologismo social; más académico, como el post-desarrollo; o de política aplicada como el buen vivir o vivir bien (sumak kawsay en kichwa en Ecuador y suma q’amaña en aymara en Bolivia, respectivamente, ambos recogidos en sus constituciones $)^{6}$. En este texto se añade la mirada desde la sostenibilidad de

3 Si bien cada vez se presta mayor atención a la inserción desfavorable en los mercados financieros: casi siempre como deudoras en lugar de acreedoras, y con condiciones de relativa desventaja. Véase varios textos en Questioning financial governance from a feminist perspective (2011).

4 Un buen análisis de esta perspectiva feminista sobre la crisis y de la alternativa que se propone en este artículo centrada en la sostenibilidad de la vida es AGENJO CALDERÓN. La autora argumenta que "lo óptimo para la Economía Feminista es unir esfuerzos para encontrar las sinergias ocultas que permitan [...] aprovechar las complementariedades que surgen de las dos corrientes” (2011: 97).

5 Este proyecto, de origen Europeo y varios siglos de consolidación, se caracteriza, según ESCOBAR (2010), por la centralidad social y discursiva del capitalismo en la economía, del liberalismo en la definición de la sociedad y la política, y por ser el estado la forma de poder definitoria de la matriz de organización social. Sin lugar a dudas, deberíamos añadir el heteropatriarcado como el contrato oculto en ese contrato social, en línea con el argumento iniciado por PATEMAN (1988).

6 Para una introducción al decrecimiento, ver por ejemplo: LATOUCHE (2008), TAIBO (2011); o los artículos contenidos en www.decrecimiento.info, red-ecomunidades.blogspot.com, www.decroissance.org, o degrowth.net. Perspectivas ecofeministas europeas pueden verse en HERRERO (2010a) y WEINGÄRTNER Y MONASTERIO MARTÍN (2010), latinoamericanas en AGUINAGA (2010). Sobre el sumak kawsay y suma q’amaña: los especiales de la Revista OBETS núm. 4 y Vol. 6 núm. 1, El buen vivir: 
la vida (Carrasco, 2009). No se plantea como la única alternativa, o la mejor de ellas, sino como una más en confluencia y comunicación con otras.

Poner la sostenibilidad de la vida en el centro significa considerar el sistema socioeconómico como un engranaje de diversas esferas de actividad (unas monetizadas y otras no) cuya articulación ha de ser valorada según el impacto final en los procesos vitales. Aquí van ligadas dos preguntas: cuál es esa vida cuyo sostenimiento vamos a evaluar, qué entendemos por vida digna de ser vivida, o de ser sostenida; y cómo se gestiona dicho sostenimiento, cuáles son las estructuras socioeconómicas con las que lo organizamos. Como argumentaremos a lo largo del texto, la construcción ética hegemónica sobre la vida es perversa en diversos sentidos. Entre otros, porque escinde vida humana y naturaleza, impone un sueño loco de autosuficiencia y negación de la vulnerabilidad, e identifica bienestar con consumo mercantil en permanente crecimiento. También están pervertidas las estructuras socioeconómicas actuales porque ponen la "vida” al servicio del capital y, por tanto, establecen una amenaza permanente sobre ella.

\section{PERO, ¿DE QUÉ CRISIS ESTAMOS HABLANDO?}

Usamos de forma recurrente el vocablo “crisis”, a veces como un fenómeno omnímodo: LA crisis; a menudo acompañado de epítetos mercantilistas: crisis de la deuda, crediticia, bancaria, de rentabilidad...; menos frecuentemente como fenómeno de corte más social o ambiental. Ante semejante polisemia, es preciso empezar por aclarar a qué nos referimos cuando usamos esta noción desde la mirada de la sostenibilidad de la vida. Para ello, tenemos que empezar por diferenciar dos momentos: el previo y el posterior al estallido financiero de 2007.

\subsection{CRISIS MULTIDIMENSIONAL ANTES DEL ESTALLIDO FINANCIERO}

Antes del estallido, las miradas críticas ya señalábamos la existencia de una profunda crisis multidimensional para referirnos, al menos, a tres cuestiones: a la crisis ecológica de dimensiones globales; a la crisis de reproducción social que afectaba al Sur global; y a la crisis de los cuidados en el Norte global ${ }^{7}$. La crisis ecológica abarca diversas dimensiones interconectadas: cambio climático, agotamiento de los recursos naturales, y colapso de la biodiversidad. Por crisis de reproducción social nos referimos a que el conjunto de expectativas de reproducción material y emocional de las personas resulta inalcanzable, pudiendo, a menudo, derivar lisa y llanamente en muerte, como ocurre con la crisis alimentaria. La noción de crisis de los cuidados afecta a una dimensión concreta de dichas expecta-

\footnotetext{
una vía para el desarrollo (2009), Suma Qamaña (2001), o portales como pydlos.ucuenca.edu.ec/buen_vivir y sumakkawsay.wordpress.com.

7 Se utiliza esta terminología para dar cuenta de relaciones de poder globales, entendiendo que este no está geográficamente concentrado. Se usarán alternativamente las nociones de centro y periferia.
} 
tivas de reproducción: los cuidados, implicando que los arreglos del cuidado son insatisfactorios, insuficientes, precarios y no libremente elegidos ${ }^{8}$.

Estas diversas dimensiones de la crisis están interrelacionadas. Los factores desencadenantes son en ocasiones comunes. Por ejemplo, la explosión del transporte motorizado y el asociado modelo de crecimiento urbano están en el corazón de la crisis ecológica, lo cual resulta más obvio ( véase, por ejemplo, Fernández Durán, 1993), pero también de la crisis de los cuidados al imponer unas condiciones sumamente desfavorables para los cuidados (Herrero, en este mismo volumen). Las dinámicas desencadenadas también están interconectadas. La crisis de reproducción social está en la génesis de la feminización de las migraciones. A su vez, el cierre reaccionario de la crisis de los cuidados deriva en la apertura de oportunidades laborales en el sector precarizado de los cuidados, nicho donde encuentran empleo cada vez más mujeres migrantes. Se conforman cadenas globales de cuidados que son la encarnación cotidiana de la expansión transnacional de un sistema socioeconómico donde la vida y su cuidado cotidiano es un asunto a resolver en lo privado y por las mujeres ${ }^{9}$.

En última instancia, lo que estábamos denunciando es que el proceso de valorización de capital se daba a costa de la explotación de los recursos naturales y de la vida humana. En el mejor de los casos, la vida y sus necesidades eran un medio para el fin de acumulación de capital; en el peor, un estorbo y lo más rentable era destruirla. A esto lo habíamos denominado conflicto capital-vida, que se intensificaba con la financiarización de la economía. Buscábamos que se reconocieran como crisis profundas y acumuladas estos gravísimos ataques a los procesos vitales, y visibilizábamos las deficiencias estructurales de un sistema depredador, que no solo era capitalista, sino también heteropatriarcal, antropocéntrico, e imperialista y, por eso y ante la dificultad de darle nombre, nos referíamos a "esa escandalosa Cosa” (Haraway, 1991). Hablábamos de crisis civilizatoria porque atravesaba el conjunto de las estructuras (políticas, sociales, económicas, culturales, nacionales), pero también de las construcciones éticas y epistemológicas más básicas (la propia comprensión de la "vida"). Y, sin embargo, no habíamos logrado consenso social para entender todo lo anterior como una crisis, sino que seguíamos hablando de procesos de "desarrollo" impulsados por la globalización de la economía de libre mercado.

8 Sobre la crisis ecológica, véase HERRERO (2010ª y en este mismo volumen); sobre la crisis de reproducción social, véase varios capítulos en Power, Production and Social Reproduction (2003); sobre la crisis de los cuidados, véase RÍO (2003), PÉREZ OROZCO (2006a y 2006b) y EZQUERRA en este mismo volumen.

9 Una introducción a la feminización de las migraciones y las cadenas globales de cuidados puede verse en PAIEWONSKY et al. (2008). 


\section{2- EL ESTALLIDO FINANCIERO Y LA RESPUESTA POLÍTICA}

Llega entonces el estallido financiero y, automáticamente y sin cuestionamiento alguno, recibe el nombre de La crisis global. Realmente, lo que se produce primeramente es una quiebra en el proceso de valorización de capital en los circuitos financieros de los países del Norte global. No es, en principio, una quiebra directa de los procesos vitales ni tampoco reviste carácter mundial. En ese sentido, no es una crisis, porque no está en crisis -0 no tan agudamente ${ }^{10}$ el proceso vital. La clave aquí es la respuesta política que se da al estallido financiero. De nuevo, tenemos que distinguir dos momentos.

La primera respuesta política implicó una breve, sorprendente y esperanzadora ruptura con el consenso post-Washington (Young et al., 2011). Se hablaba de refundar las bases del capitalismo y de poner coto a los mercados financieros. Se apostaba por medidas de corte keynesiano, que promovían la recuperación de la actividad mercantil mediante inyecciones de dinero público en ciertos sectores financieros y productivos. Esta respuesta política inicial puede leerse como el intento de recuperar las tasas de ganancia salvaguardando al mismo tiempo las condiciones de vida de la población a través de la protección del empleo y los niveles de consumo. Dicho de otra forma, como un intento de conciliar los procesos de acumulación de capital y de sostenibilidad de la vida; una apuesta por la "producción” frente a las finanzas. En el estado español, el Plan E fue el máximo exponente de este ciclo.

Desde una perspectiva productivista, esta reacción puede considerarse acertada. Desde el feminismo se planteó incluso como una "ventana de oportunidad" para dirigir la inversión pública hacia sectores intensivos en mano de obra que implicaran la socialización del cuidado y oportunidades de empleo para las mujeres ${ }^{11}$. Desde una perspectiva de sostenibilidad de la vida, la valoración no es tan halagüeña. La gran debilidad intrínseca era que esa respuesta consistía en una apuesta por negar la existencia de esa contradicción profunda capital-vida. El breve lapso que duró mostró que la vía de la paz social tiene unos límites clarísimos: cuando la situación exige hacer renuncias al proceso de valorización, llega el ataque desde ahí, porque es en él donde reside el poder. El conflicto se desata desde el terreno que pone en jaque la vida misma.

10 Si bien es cierto que esa quiebra de los procesos de valorización en los mercados financieros, primero, transmitida luego al ámbito de la "producción”, sí está directamente vinculada con el incremento sostenido de la desigualdad y con lo que se ha venido a denominar el "ajuste salarial permanente" (ÁLVAREZ PERALTA, 2011), que implica en sí un ataque directo a las condiciones de vida. Igualmente, el estallido financiero sí tiene un inmediato y gravísimo impacto en las condiciones de vida de ciertos segmentos sociales, sobre todo, aquellos que habían suscrito las llamadas hipotecas basura, donde las mujeres y, particularmente, las mujeres negras estaban sobre-representadas a consecuencia de lo que YOUNG ET AL. (2011) denominan el "sesgo del crédito" y el "sesgo del riesgo".

11 En esta línea van ANTONOPOULOS (2009) y GÁLVEZ Y TORRES (2009). 
Así se pasó al segundo momento de la respuesta política en el cual estamos inmersxs ${ }^{12}$ a día de hoy, caracterizada por el hecho de que los estados se escoran hacia las necesidades y exigencias de los mercados financieros. Se están socializando los riesgos del capital con medidas tales como los rescates bancarios, los diversos mecanismos que implican la socialización de la deuda privada de bancos y grandes empresas, y la apertura de nuevos nichos de mercado con la privatización de instituciones financieras y servicios públicos. Al mismo tiempo, se privatizan los riesgos de la vida, los de la ciudadanía misma, con el conjunto de medidas que forman parte de los paquetes de austeridad y recorte ${ }^{13}$.

Esta privatización implica un estrechamiento del nexo calidad de vida-posicionamiento en el mercado: el acceso a recursos deja de tener algún tipo de garantía colectiva y queda en manos privadas (a lo que los hogares acceden vía mercado o vía trabajo no remunerado). Todo ello a la par que empeora el acceso a fuentes estables y suficientes de ingresos y que se desregula el mercado laboral, implicando un peor acceso a derechos sociales y una individualización de la negociación de las condiciones laborales. En definitiva, tienden a desaparecer los ya de por sí insuficientes mecanismos colectivos para garantizar el acceso a condiciones de vida dignas en términos de universalidad e igualdad, y en contraste se refuerzan los mecanismos que colectivizan la responsabilidad de garantizar la generación de tasas de ganancia suficientes para el capital. Es un ataque directo a los procesos de sostenibilidad de la vida. Aquí sí ya podemos y debemos hablar de crisis.

\section{4 •¿QUIÉN Y CÓMO SE ENCARGA DEL AJUSTE?}

El proceso de valorización en los mercados financieros quiebra y el estado responde, readaptando su papel para que dicho proceso se recupere. ¿Dónde se produce el ajuste final, en términos de reacomodar el proceso de sostenibilidad de la vida a las nuevas condiciones impuestas por los mercados financieros? Ante este sesgo del estado y la inexistencia de otro tipo de mecanismos de respuesta colectiva, es en los hogares donde se sigue intentando garantizar la generación cotidiana de bienestar. Los hogares se las ingenian para afrontar el contexto de, por un lado, privatización del acceso a los recursos y de la gestión de los riesgos vitales, y, por otro, pérdida de fuentes de ingresos estables y suficientes. Una vez más, se ve lo ya constatado para otras crisis: son los hogares el colchón último del sistema socioe-

12 En este texto hemos optado por substituir la @ por una x, considerando que esta es una forma más inclusiva porque, además de abarcar los géneros masculino y femenino, abre espacio para los sujetos transgénero, que se reivindican en tránsito, o en algún lugar intermedio.

13 Recorte del gasto público, reforma fiscal regresiva, desregulación del mercado laboral, privatización de los pilares del estado del bienestar (sistemas de pensiones, sanitario y educativo). 
conómico, el lugar donde en última instancia se absorben los shocks que se producen en otras esferas ${ }^{14}$.

\section{1- NUEVAS ESTRATEGIAS DE SUPERVIVENCIA: PRIVATIZADAS, GLO- BALES Y FEMINIZADAS}

¿Cómo se produce este ajuste? Mediante el despliegue de "nuevas estrategias de supervivencia”. Entre ellas podemos mencionar, al menos, tres ${ }^{15}$. En primer lugar, la búsqueda de nuevas fuentes de ingresos, intentando encontrar empleo en sectores que se habían abandonado; por ejemplo, la vuelta al sector agrícola o al empleo de hogar de parte de la población autóctona. O bien con la inserción en el mercado laboral de sujetos que antes estaban fuera, como es el caso de las mujeres mayores de cincuenta y cinco años ${ }^{16}$. Esto supone una transformación de los roles económicos de los sujetos y una comprensión diferente de la "normalidad económica"17. A la par se van volviendo borrosas las fronteras que separan la economía formal de la informal, en una vuelta de tuerca al ya señalado proceso de "domesticación del trabajo", que abarca y desborda el fenómeno de precarización del empleo ${ }^{18}$. Tener un empleo es cada vez menos garantía de acceso a salario indirecto o diferido (prestaciones y derechos contributivos). ¿Puede empezar a expandirse la realidad de los "trabajadores pero pobres"19?

En segundo lugar, se produce una traslación de costes y responsabilidades hacia el trabajo no remunerado. Si ya no es posible acceder a ciertos bienes y servicios de mercado y hay otros que el sector público deja de proporcionar, una alternativa es reducir los niveles de consumo. Pero hay otros recursos de los que no se puede prescindir, y cuya producción se vuelca al trabajo no pagado. Esto es claro con los

14 En la crisis se ve con nitidez que la economía es un circuito integrado, donde interactúan los diversos agentes (empresas, instituciones públicas y hogares). Ante cambios en una esfera, el resto también se recolocan. La clave es que la responsabilidad final de garantizar que el conjunto "encaje" se asume en los hogares (está privatizada), en gran medida a través de los trabajos no remunerados, que juegan un triple papel económico: expansión del bienestar, ampliación del bienestar y selección de la parte de la población que se integra en el mercado como fuerza laboral (PICCHIO, 2001).

15 AGENJO (2011) recoge literatura sobre las dos primeras.

16 Su tasa de actividad mercantil se ha incrementado un 42,6\% (de 11,81 el tercer trimestre de 2006 a 16,72 en el tercero de 2011) según datos de la Encuesta de Población Activa.

17 En este contexto surgen afirmaciones como las del senador republicano Newt Gingrich proponiendo que lxs niñxs de clases desfavorecidas puedan trabajar a partir de los nueve años; declaraciones que, si bien aún suenan a exabrupto en el Norte global, pueden ir adquiriendo carta de normalidad, como lo han hecho en el Sur global a raíz de los planes de ajuste que desencadenaron la crisis de reproducción social (http://www.nytimes.com/2011/12/04/opinion/sunday/dowd-out-of-africa-and-into-iowa.html).

18 Véase por ejemplo en PÉREZ OROZCO (2006a).

19 Con este término (working poor) se hace referencia a una nueva modalidad de pobreza que ataca no a quienes no tienen empleo, sino a quienes sí lo tienen: "El concepto de working poor nos sirve para referirnos a aquellas personas que, a pesar de tener una relación laboral normalizada (con contrato legal) se sitúan por debajo del umbral de pobreza de su país” (MEDIALDEA y ÁLVAREZ, 2005: 57). 
cuidados a raíz de los recortes en el gasto público. Ya en otras crisis se ha denunciado la derivación de costes a estos trabajos, que de manera implícita se dan por infinitamente flexibles. La crisis se "resuelve" trasladando una enorme carga laboral a ciertos segmentos sociales (mayoritariamente mujeres).

En tercer lugar, se despliega lo que se ha denominado una "economía de retales" 20 , en la que los diferentes miembros de los hogares ponen en común todos los recursos disponibles (de tiempo, haciendo gratis cosas que antes se compraban; de dinero, generando flujos financieros alternativos e informales; espaciales, compartiendo casa; de información, etc.). Esto unido a una ampliación de las fronteras del "hogar", con una vuelta a la familia nuclear de jóvenes (y no tan jóvenes) que se habían emancipado parcialmente, o con un reforzamiento de la familia extensa. Esta economía de retales es sumamente elocuente de una cuestión clave sobre la que volveremos: la realidad económica es una realidad de interdependencia. La cuestión es que la red que se hace cargo de esa interdependencia sigue estando sumamente asociada a los modelos tradicionales de familia; no parece que surjan formas alternativas de organizar la convivencia y de compartir recursos... ¿ ¿es esto realmente así? En ese caso, ¿̇por qué?

Difícilmente podemos contestar a esas preguntas, porque de estas nuevas estrategias de supervivencia sabemos poco. De la que más datos disponemos es de la primera dada la focalización de las estadísticas en el mercado laboral. Pero la domesticación del trabajo supone que proliferan realidades laborales borrosas, difícilmente captables con categorías pensadas para el mercado laboral formal. Tampoco sabemos bien qué está pasando en el empleo de hogar y en el trabajo sexual, sectores históricamente feminizados (siempre mal captados por los sistemas de medición androcéntricos), cuyo comportamiento se define por pautas propias en parte ajenas al "clima económico" general y que funcionan como nichos laborales de emergencia cuando los socialmente aceptados fallan. Para visualizar la segunda tampoco tenemos casi datos, entre otras cosas, porque las encuestas de usos del tiempo se realizan cada grandes intervalos de tiempo ${ }^{21}$. Y sobre la tercera cabe decir que no se presta suficiente atención a este ámbito micro de ajuste del sistema. Son pequeños aspectos de la cotidianeidad, imperceptibles para las estadísticas al uso, las visiones macro y la mirada de la teocracia mercantil que, sin

20 RIBAS-MATEOS lo explica como "las diferentes formas de utilizar todos los recursos disponibles por las familias" (2005: 264).

21 En el estado español hay dos oficiales (2002-2003 y 2009-2010). Este largo intervalo se argumenta aduciendo que los cambios en la distribución de los trabajos no remunerados responden a transformaciones estructurales y no a variaciones coyunturales. Se afirma que son encuestas caras, y que no merece la pena hacerlas a menudo. Además de preguntarnos sobre lo relativo de qué se considera o no costoso, hay alternativas. En Ecuador, por ejemplo, además de realizar encuestas de usos del tiempo detalladas con lapsos más largos, se introduce un pequeño módulo al respecto en las encuestas de mercado laboral trimestrales. Esto ha permitido ver que, efectivamente, ante la crisis de 2007 hubo un claro aumento del tiempo dedicado a trabajo no remunerado, diferencial por clase social y por sexo (VÁSCONEZ, 2009). Este papel contracíclico lo identifica también DURÁN (2011). 
embargo, son clave para comprender el impacto en el bienestar efectivo de los sujetos concretos. Para entender estas estrategias convendría tener muy en mente lo ocurrido en el Sur global a raíz de la imposición de programas neoliberales muy similares a los actuales en el Norte global.

A pesar de esas carencias, algo sabemos. Merece remarcar dos características de estas nuevas estrategias de supervivencia, además del hecho de que estén privatizadas (relegadas a los hogares). El primer elemento a destacar es que son globales; no se toman pensando en el estricto ámbito de los estados-nación, sino en términos transnacionales. La gente está migrando o proyectando migrar; tanto quienes lo habían hecho previamente como quienes inician una nueva migración ${ }^{22}$. La crisis no puede pensarse ni afrontarse desde una perspectiva constreñida a las fronteras nacionales no solo porque los mercados están globalizados, sino porque hemos construido y seguimos reforzando lazos interpersonales de carácter global.

Los países del centro estamos cada vez formando parte del proceso de globalización de las migraciones en calidad de "países de origen”. Esto obliga a nuevas miradas sobre la migración y a tener cuidado en comprender los dinámicos procesos de segmentación social a lo que esto dé lugar. En un contexto de hegemonía mundial y de mercados laborales etno-segmentados, la migración del Sur hacia el Norte implicaba la inserción de la población migrante en los estratos más bajos del mercado laboral, dando lugar a nuevos tipos de "clases sirvientes" (Sassen, 2008); a su vez, la migración desde el Norte puede implicar la aparición (o engrosamiento) de nuevas élites blancas que copen los estratos superiores del mercado laboral de muchos países del Sur global. Todo ello en un contexto de periferización de algunos países del centro.

El segundo elemento a destacar es que se trata de estrategias feminizadas o, dicho de otra manera, que el ajuste está sexuado. Mientras que la construcción de la identidad masculina se entiende como la construcción de sí para sí a través del mecanismo clave del trabajo en el mercado; la construcción de la feminidad pasa por la construcción de sí para el resto a través de la realización del conjunto de trabajos y actividades necesarios para que el hogar salga adelante (Murillo, 1996). El desempleo masculino a menudo deriva en un doloroso proceso de pérdida de identidad y de "sentido de la vida". Frente a ello, quienes tienden a reaccionar son las mujeres, buscando nuevas fuentes de ingresos, intensificando el trabajo no pagado, o creando redes de intercambio. Es decir, desplegando las estrategias de las que hablábamos. A pesar de las fugas y fracturas que se estaban produciendo en esta forma de entender a los sujetos sexuados, cabe preguntarse si, en momentos de crisis, no tienden a reforzarse. Necesitamos mirar atentamente este proceso. Este es

22 Según INE (2011), si se mantienen las tendencias actuales el estado español perdería casi un millón de habitantes entre 2011 y 2020. 
uno de los terrenos clave en los que los feminismos han de aportar a la comprensión de la crisis ${ }^{23}$.

\section{2- HIPERSEGMENTACIÓN Y CRISIS DE REPRODUCCIÓN SOCIAL}

¿Son suficientes estas estrategias para ajustarse a las nuevas condiciones de privatización de los riesgos de la vida? Claramente no lo son, o no para todas las personas ni todos los grupos sociales. Si nada cambia, va a intensificarse un proceso de hipersegmentación social y a generarse una crisis de reproducción social.

Con la respuesta política al estallido, hay ciertos grupos sociales que están enriqueciéndose. Se socializan los riesgos de ciertas élites financieras, en cuyas manos se va concentrando la riqueza; este proceso de concentración adquiere un ritmo vertiginoso en el momento actual. Frente a este acaparamiento por parte de una minoría de la población mundial, amplios segmentos sociales viven un proceso de intensificación de lo que desde el feminismo habíamos llamado "precariedad en la vida" 24 . Las dimensiones de esta precariedad que van a agravarse así como la virulencia de dicha intensificación no van a ser uniformes ni homogéneas. En otros casos, de una situación de precariedad se irá pasando a una situación de exclusión. Decíamos hace tiempos que entre la precariedad y la exclusión no había solución de continuidad, y que, de hecho, la exclusión funcionaba como una amenaza para acatar la pérdida de derechos que estaba en la génesis de la precariedad. Es imprescindible estar pendientes para conocer quién, cómo, por qué mecanismos y en qué sentidos está pasando de la inseguridad en el acceso a recursos, al no-acceso. Caso claro es el de la irregularidad sobrevenida, que afecta a personas migrantes que tenían una situación administrativa ya regularizada, pero que, al perder el empleo y dejar de cotizar, pierden "los papeles", pudiendo llegar a situaciones absurdas en las que sean no-ciudadanxs, pero sí estén hipotecadxs. Otro caso es el de las mujeres viviendo situaciones de violencia machista que no pueden separarse por el agravamiento de las dificultades financieras.

Lo que presenciamos no es una cuestión de dualización social, sino un fuerte aumento de las desigualdades sociales ${ }^{25}$. El impacto de la crisis varía según diver-

\footnotetext{
23 Para hacerlo, es preciso la confluencia de miradas, entre aquellas más preocupadas por los procesos “materiales” y las más pendientes de los aspectos “subjetivos y simbólicos”. Un acercamiento que lamentablemente no es fácil ni fluido. La economía feminista está en gran medida anclada en el sujeto clásico “mujer” y tiene poca capacidad para comprender los cambios en los roles de género (partiendo además de nociones sumamente binaristas de los sujetos sexuados). Frente a ello, otras corrientes como la teoría queer a menudo parecen sobredimensionar los cambios y no ver que, en momentos críticos como el actual, el papel en torno al reparto de los trabajos y a la asunción final de las responsabilidades sigue destilando tintes muy clásicos.

24 Al hablar de precariedad en la vida no nos referíamos a si se tiene una vida más o menos estable, sino a la inseguridad en el acceso sostenido a los recursos y mecanismos que permitan tener una vida libremente elegida. Véase PRECARIAS A LA DERIVA (2004) y RÍO y PÉREZ OROZCO (2004).

25 Sobre la evolución de la desigualdad, véase el reciente informe de la OCDE (2011).
} 
sos factores, todos ellos a su vez con dimensiones de género: De forma clave el posicionamiento de cada quien en los mercados (si se tiene o no acceso a rentas no salariales, y cuál es la inserción que se tiene en el mercado laboral), pero también de otros elementos como las redes familiares o sociales de las que se disponga y el estatus de ciudadanía. Los procesos de inclusión/exclusión no son limpios, sino que discurren a lo largo de un hilo de continuidad donde las vías y las dimensiones mismas de la exclusión son sumamente complejas y diversas. La desaparición de mecanismos colectivos de gestión de la vida, en general, y de los riegos de la vida, en particular, lo que permiten es que se desplieguen en todo su esplendor los mercados, poderosas instituciones de multiplicación de las desigualdades.

En última instancia, decir que el ajuste de y en los hogares es insuficiente significa decir que la crisis multidimensional que precedía al estallido financiero va a agravarse. Las preocupaciones ecológicas pierden el poco fuelle que tenían frente a lo que se perciben como los verdaderos problemas graves y urgentes. La crisis de los cuidados en el centro se agudiza por la pérdida de servicios y prestaciones públicas, la traslación de cargas al trabajo no remunerado y la posibilidad de que se deteriore el estado general de salud ${ }^{26}$. Y la crisis de reproducción social, además de poder agravarse en los países del $\operatorname{Sur}^{27}$, sin lugar a dudas va a comenzar a ser una realidad cotidiana en los países del Norte.

\section{ENTONCES: ¿PRODUCIR O REPRODUCIR?}

La economía feminista se caracteriza por la vocación de intervención, por analizar lo que ocurre para poder hacer propuestas políticas; es feminista en la medida en que contiene en sí una pretensión de subversión. ¿¿Qué pretende subvertir, qué pretender transformar ante esta crisis civilizatoria?

Desde las visiones productivistas, la clave es recuperar el "crecimiento económico”, la "producción” y sus bondades asociadas (el empleo, los salarios, el consumo). El feminismo productivista pone también aquí el énfasis, reivindicando que esa recuperación no se haga forzando a las mujeres a volver a los hogares (evitando que, en un contexto de escasez de puestos de trabajo, estos se adjudiquen priori-

\footnotetext{
26 En otro lugar hemos argumentado que la precariedad en la vida incrementa las necesidades de cuidados y reduce las posibilidades de recibirlos, esto es, agrava la crisis de cuidados (RÍO y PÉREZ OROZCO, 2004). Gil (2011a) llega a afirmar que otra de las dimensiones de la crisis multidimensional es una grave y profunda "crisis de la salud".

27 En este texto no vamos a entrar en el debate sobre si la crisis post-estallido es global (o va a llegar a serlo y qué grado de autonomía han logrado articular algunas regiones para mantenerse relativamente al margen), o si estamos poniendo la etiqueta global a una crisis que tiene su epicentro en los países del Norte global (mostrando cómo quien ocupa la posición hegemónica puede convertir sus problemas en los problemas de todxs; al igual que el capital financiero ha logrado que asumamos como propia su crisis). En todo caso, la crisis multidimensional vista desde una óptica de sostenibilidad de la vida sí es global, y tiene un largo recorrido histórico, no es nueva.
} 
tariamente a los hombres) y/o que no refuerce un modelo de ganador y medio (copando los hombres los puestos a tiempo completo y dejando a las mujeres encasilladas en el tiempo parcial). Estas reivindicaciones levantan importantes debates sobre la autonomía monetaria y el acceso a derechos de las mujeres, pero siguen insertas en una lógica de "competencia por los empleos" que, en última instancia, es indicativa de un problema más profundo: el gran error es en sí la reivindicación de la producción.

La idea de la "producción” ha recibido fuertes críticas desde varias miradas, entre ellas, el ecologismo social y el feminismo. Desde el ecologismo social y la economía ecológica se afirma que la "metáfora de la producción” (Naredo, 2006) se ha adueñado de nuestra forma de interpretar el mundo, generando una falsa creencia en la capacidad de producir riqueza como un proceso progresivo y creciente sin límite. Este sería el objetivo socioeconómico por excelencia: el progreso y el desarrollo entendidos como crecimiento sin fin. A su servicio estaría el planeta, el conjunto de recursos naturales disponibles para que el hombre (en su acepción metonímica) los domeñe y utilice para ir constituyendo civilización. Sin embargo, los sistemas socioeconómicos son subsistemas abiertos, que extraen recursos y absorben energía, y generan residuos y emiten energía degradada. Estos subsistemas abiertos funcionan en un sistema cerrado, la biosfera, que no intercambia materiales con el exterior y muy poca energía (la solar); en este sistema cerrado la única producción es la de la fotosíntesis, y es muy poca. Es decir, extraemos y transformamos, pero no producimos nada. La producción no existe, es una fantasía antropocéntrica que tiene una única forma de mantenerse: disponer de un medio fantasma de acumular esa supuesta riqueza creada, el dinero. El dinero, que no existe más que en la medida en que la gente crea que existe (podemos decir que es una realidad de carácter performativo, (Cornwall, 1998), no solo se convierte en el fin del proceso económico, en medio de acumulación y no de mero intercambio, sino que es el sine qua non para el funcionamiento de la metáfora de la producción.

Desde el feminismo se afirma que el otro oculto de la producción es la reproducción, en un esquema epistemológico heteropatriarcal que está en la base de la explotación de la naturaleza y la opresión de las mujeres. Este esquema se caracteriza por interpretar el mundo de manera dicotómica: comprender la realidad organizada en pares opuestos (bueno/malo, producción/reproducción), con una valoración jerárquica del binomio (la producción es el progreso, lo deseable) y donde el miembro valorado termina arrogándose el todo, la universalidad (solo vemos y hablamos de la producción). Además, hay un encabalgamiento entre toda dicotomía y las dos clave de masculino/femenino, civilización/naturaleza. La producción encarna valores de la masculinidad, y usa la naturaleza feminizada para construir civilización. Desde aquí, se produce una disociación entre la producción, el progreso, objetivo civilizatorio, y la mera reproducción, el sostenimiento, condición que debe superarse. Desde aquí, la economía de mercado es un estadio de civilización superior a las "economías de subsistencia", porque permite colmar deseos, y no simplemente satisfacer necesidades. Lo plenamente humano es crecer, poner la 
vida al servicio de algo superior a la vida misma. Ante esta epistemología perversa, la cuestión no es solo visibilizar que, además de producir bienes y servicios, también se reproducen personas. Sino señalar que ambos procesos no están escindidos, que la producción solo nos importa en la medida en que reproduce vida. La reproducción es la lente desde la que mirar el conjunto, el eje trasversal. Y no hay contradicción entre el objetivo de "vivir bien" y la sostenibilidad. Se trata de apostar por una vida que merezca la pena ser vivida, en palabras de Tortosa (2009): Buen Vivir es "la idea de una vida no mejor, ni mejor que la de otros, ni en continuo desvivir para mejorarla, sino simplemente buena”.

El proceso de financiarización supone una vuelta de tuerca en esas perversiones. Por un lado supone que el dinero, por primera vez, es capaz de crear dinero, perdiendo de vista toda noción de los límites físicos, disociando por completo la idea de "crecimiento" de la materialidad que lo sustenta. Por otro lado, la financiarización supone un agravamiento del conflicto capital-vida ${ }^{28}$, al establecer plazos cada vez más cortos para satisfacer el proceso de valorización de capital, generándose una disociación absoluta con los ritmos vitales (los de todos los procesos naturales, incluidos los humanos). Con la financiarización, la "economía real” se pone al servicio de las finanzas, cierto, pero la base invisibilizada que sostiene el conjunto sigue siendo la "reproducción", el conjunto de esferas donde se recluye la responsabilidad de sostener la vida en un sistema que coloca la vida al servicio del proceso de valorización (en el ciclo del capital industrial y/o mercantil, antes; del capital financiero, ahora).

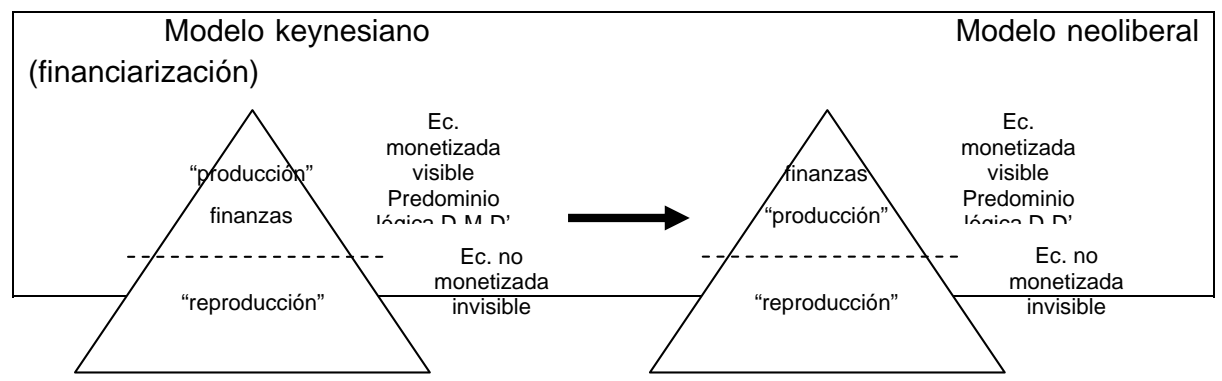

Por todo ello, la desfinanciarización de la economía (el conjunto de medidas tendentes a poner control en ese "casino global”) es clave, pero encierra en sí preguntas que van más allá: ¿cuál es el objetivo?, ¿un mayor control y transparencia?, ¿unas finanzas que no estén bajo la lógica de valorización, apostando, por ejemplo,

28 Si bien sabemos que este conflicto es inherente en el capitalismo heteropatriarcal, puede tener diversas intensidades. Y en el paso de la lógica del capital industrial (D-M-P-M'-D') a la lógica del capital financiero (D-D’) se había agravado. Sobre este conflicto y la metáfora del sistema económico como un iceberg, véase PÉREZ OROZCO (2006a y 2006b). 
por una banca pública?, ¿el establecimiento de pequeñas entidades financieras cercanas a la comunidad y bajo control democrático local? O, incluso ¿queremos un nuevo papel del dinero, volviendo a situarlo como medio de intercambio y no de acumulación? ¿Queremos que el dinero tenga algún tipo de vínculo con los recursos naturales existentes? ${ }^{29}$ No se trata de cuestionarnos cómo volver a poner las finanzas al servicio de la producción (introduciendo ciertas enmiendas, entre ellas, la garantía de plena igualdad de oportunidades para mujeres y hombres), sino de preguntarnos cómo reproducir las condiciones de posibilidad de una vida que merezca la pena ser vivida, y de qué flujos materiales y de energía disponemos realmente para lograrlo.

\section{DOS DEBATES: QUÉ VIDA SOSTENER Y CÓMO HACERLO}

Ante la crisis civilizatoria, tenemos que abrir muchos debates y, de forma clave, los dos siguientes: a qué nos referimos cuando hablamos de una vida que merece la pena ser sostenida; y con qué estructuras reproducimos sus condiciones de posibilidad.

\section{1- UNA VIDA QUE MEREZCA LA PENA SER VIVIDA}

¿De qué vida estamos hablando? Al hablar de "la vida” hay un riesgo implícito de pensar que "existe una vida más allá del capitalismo, como si toda vida no estuviese ya inmersa en las relaciones actuales de dominio: de nuevo, existe el peligro de esencializar la vida, crear una especie de paraíso en algún lugar utópico al que deberíamos poder acceder" (Gil, 2011b: 304-5). Para evitarlo, necesitamos entender qué se entiende por vida que merece la pena en el capitalismo heteropatriarcal; y preguntarnos qué vida nos merece la pena bajo nuestros propios (otros) criterios éticos.

El capitalismo heteropatriarcal impone como objetivo vital la autosuficiencia en y a través del mercado. Esta autosuficiencia es un espejismo que solo se mantiene en base a ocultar las dependencias y a los sujetos que se hacen cargo de ellas. En momentos de crisis muestra su tremenda fragilidad, su imposibilidad de materializarse salvo en momentos muy puntuales (siendo joven, teniendo plena salud, careciendo de responsabilidades de cuidados) y cuando el contexto mercantil es favorable; en cuanto alguno de esos elementos quiebra, vemos que nos necesitamos unxs a otrxs. Por el contrario, necesitamos partir de una condición ontológica fundamental: la materialidad de la vida y los cuerpos. La vida es vulnerable y finita; es precaria, si no se cuida, no es viable. De ahí que debamos preocuparnos por establecer sus condiciones de posibilidad, que no son automáticas: "la vida exige que se cum-

29 En esta línea va la propuesta lanzada por José Manuel Naredo en su breve artículo de opinión Materias primas y sistema financiero internacional (“Público”, 1 de marzo de 2011). 
plan varias condiciones sociales y económicas para que se mantenga como tal" (Butler, 2009: 30). La única vía para hacerse cargo de la vulnerabilidad y la precariedad es en la interacción: "La precariedad implica [...] la dependencia de unas personas que conocemos, o apenas conocemos, o no conocemos de nada" (Butler, 2009: 30) Reconocer la vulnerabilidad no es reconocer un mal, sino la potencia que hay ahí: la posibilidad de sentirnos afectadxs por lo que les ocurre al resto, y la constatación de que la vida es siempre vida en común, en interdependencia; y en ecodependencia, dependemos de los recursos naturales y energéticos que nos sustentan.

$\mathrm{Al}$ abrir el debate ético sobre qué vida merece la pena ser sostenida partiendo del reconocimiento de la vulnerabilidad, la interdependencia y la ecodependencia, hemos de adentrarnos en numerosas cuestiones. Entre ellas, señalemos tres, haciendo unos breves apuntes sobre los aportes específicos que los feminismos puede hacer. Primero: ¿qué es “vivir bien”30? ¿Qué necesidades han de ser cubiertas? Esta pregunta no ha de plantearse en términos individuales; la cuestión es dilucidar de qué necesidades nos vamos a hacer cargo colectivamente. Los aportes feministas van en varias líneas: enfatizar la indisolubilidad de las dimensiones materiales y afectivas de las necesidades; cuestionar la dicotomía deseo (más allá del sostenimiento)/necesidad (sostenimiento); y remarcar la importancia de la necesidad de cuidados como propia de todas las personas a lo largo de todo el ciclo vital. Planteamientos como el decrecimiento enfatizan la noción de que la respuesta ha de darse desde la plena conciencia de los límites de la biosfera y de que hemos entrado en una fase de "translimitación".

Segundo, cómo gestionar esa interdependencia inevitable. Si vamos a seguir haciéndolo bajo relaciones de asimetría y jerarquía, donde ciertos sujetos o colectivos, asociados a la feminidad, son unilateralmente calificados como dependientes (con las connotaciones de parasitismo que de aquí se derivan); mientras que otros, asociados a la masculinidad, son socialmente legitimados como independientes en aras de sus aportes a los mercados. La cuestión es cómo hacer para que la interdependencia se dé en términos de reciprocidad. El feminismo añade una cuestión esencial: cómo combinar esa interdependencia con niveles suficientes de autonomía, entendida como capacidad de decidir sobre la propia vida, sabiendo que "la autonomía personal y la autonomía social mantienen una complicidad [...] una no puede darse sin la otra” (Gil, 2011b: 124).

Tercero, cómo nos comprendemos los sujetos sexuados que vivimos esa vida. En el capitalismo heteropatriarcal, la feminidad se construye diluyendo la indivi-

30 Buen vivir o vivir bien en las propuestas del sumak kawsay y suma q'amaña que mencionábamos en el apartado 2; lo que BUTLER (2009) llamaría "vida vivible"; lo que en este artículo denominamos "vida que merece la pena ser vivida" o ser "sostenida"... Como queramos llamarlo. Desde distintas ópticas se usan diversos nombres. No disponer aún de un vocablo claro y cerrado no es un signo de debilidad de los planteamientos sino, muy al contrario, de su fortaleza y dinamismo, del estar en plena ebullición y de la posibilidad de entrar en diálogo. 
dualidad en los otros, bajo una ética reaccionaria del cuidado, que produce lo que María Jesús Izquierdo denomina un "sujeto dañado"; no es este el lugar desde el que construir práctica política. Tampoco lo es la subjetividad construida en torno al modelo hegemónico de masculinidad, que pretende aproximarse al ideal de autosuficiencia perverso. En el momento de crisis corremos el riesgo de que estas construcciones sexuadas se refuercen, pero es también el momento clave para cuestionarlas y para preguntarnos cómo articular otras formas de estar en el sistema socioeconómico que sean liberadoras, y que, al mismo tiempo, sean capaces de comprometerse, de asumir una responsabilidad por el otro y la otra, por el colectivo. De nuevo, los aportes potenciales de los feminismos son clave.

\section{2- HACIA UNA RESPONSABILIDAD COLECTIVA EN EL SOSTENIMIENTO DE LA VIDA}

Si la primera pregunta es de corte ético, la segunda que es de corte más político: de qué estructuras socioeconómicas nos dotamos para articular una responsabilidad colectiva en la reproducción de las condiciones de posibilidad para esa vida que merece la pena ser vivida. En el sistema actual, la preeminencia del proceso de valorización de capital implica que la vida éticamente cualificada está siempre bajo amenaza $^{31}$. Como lo afirma Herrero (2010b), es un sistema "biocida". La responsabilidad de sostenerla está privatizada, feminizada e invisibilizada. De aquí se abren múltiples debates, y, al menos, dos certezas: la propuesta no es dejar esa responsabilidad en los mercados capitalistas; estos no pueden ser la estructura socioeconómica priorizada, sino que, antes al contrario, han de tender a desaparecer. A la par, esa responsabilidad ha de ir democratizándose, colectivizándose y des-feminizándose. Si bien pueden parecer afirmaciones excesivamente amplias y abstractas, de ellas se deriva un primer movimiento estratégico fundamental: detraer recursos de la lógica del capital, para poder ponerlos a funcionar bajo otras lógicas económicas (de reciprocidad y solidaridad) en estructuras económicas democráticas. Para

31 De nuevo, hay un riesgo implícito de esencialización de "la vida”. Siendo este un debate complejo que ameritaría mayor discusión, señalemos al menos tres cosas: la vida reconocida en sus dimensiones ontológicas de vulnerabilidad e interdependencia no puede ser asumida en el capitalismo porque se basa en el ideal (heteropatriarcal) de autosuficiencia y omnipotencia. En ese sentido, siempre hay dimensiones de la vida no rentables (no se cubren mediante el consumo mercantil). Eso no es óbice para que el capitalismo heteropatriarcal construya un ideal vital que resulta sumamente estimulante, y aquí deberíamos utilizar nociones como el biopoder o el biocapitalismo. El capitalismo heteropatriarcal no se impone a la fuerza sobre nuestras concepciones de las vidas que merecen, sino que nuestra propia noción de la misma, nuestras subjetividades, responden a sus mecanismos. Como lo afirma María Jesús Izquierdo, el capitalismo es droga pura, engancha no tanto por lo que te da, sino por lo que promete dar y nunca llega a darte. Y, por último, si hablamos de una vida éticamente cualifica bajo los criterios de universalidad y de igualdad (en la diversidad), cabe decir que la vida en el capitalismo es insostenible porque el bienestar de una parte se sustenta siempre sobre otra, porque siempre hay vidas enteras que no resultan rentables (ni en tanto que fuerza de trabajo ni en tanto que consumidoras) y porque es un sistema inherentemente jerárquico. 
lograrlo, disponemos de una plétora de mecanismos, que implican una detracción más o menos amplia, intensa o directa ${ }^{32}$. Pongamos varios ejemplos:

Para detraer espacio físico (tierra, espacio urbano y rural) el ecologismo tiene muchas propuestas elaboradas: recalificación y/o reclasificación de los suelos; redefinición de la orientación de los transportes, priorizando el colectivo frente al automóvil y una red ferroviaria electrificada que una todos los núcleos habitados y priorice esta conexión frente a las líneas de alta velocidad que unen grandes núcleos; espacio en las ciudades para el carril bici y zonas peatonales frente al asfalto para los coches; tierras para la pequeña agricultura ecológica frente a las tierras para los monocultivos para la exportación... Para detraer viviendas, hay propuestas más reformistas como la dación en pago, y otras más rupturistas, como la expropiación de la vivienda vacía y la puesta en marcha de un parque público de vivienda en alquiler; o la okupación misma.

En este debate es imprescindible introducir la pregunta sobre los cuidados. En su caso, más que detraerlos de la lógica de acumulación, se trata de evitar que continúe la tendencia actual de que entren en ella. En ese sentido, la propuesta fundamental sería prohibir que los cuidados puedan ser servicios proporcionados por entidades con ánimo de lucro, retomando la vieja idea de que el ánimo de lucro no puede operar en sectores básicos, y exigiendo que los cuidados sean considerados como tal.

Para detraer recursos financieros, dinero, hay muchas herramientas, entre ellas, persecución del fraude fiscal, abolición de los paraísos fiscales, expropiación de bancos y creación de una banca pública. Quizá especialmente bien hilada está la propuesta de realizar una reforma fiscal progresiva que implique la priorización de los impuestos directos sobre los indirectos; gravar más al capital que al trabajo; y establecer un sistema de tipos y tramos realmente progresivo, tanto para el capital como para el trabajo. Podríamos añadir que una reforma fiscal progresiva debería eliminar los mecanismos que redistribuyen hacia los modelos normativos de familia.

Todas esas propuestas van en la línea de que, frente a la "crisis de la deuda” y los asociados problemas de déficit público, la vía de reacción ha de ser aumentar los ingresos públicos en lugar de reducir el gasto. Pero la pregunta de fondo es: ¿para qué usar estos recursos? ¿Recaudarlos para ponerlos a funcionar otra vez en los mismos circuitos, por ejemplo, financiar otro mega-proyecto? ¿Para que la gente pueda satisfacer expectativas de consumo insostenibles, por ejemplo, comprar otro coche nuevo? La idea no es "reactivar la demanda" (cualquier demanda, de cualquier necesidad) para incrementar la "producción real”, sino preguntarnos

32 Podemos por ejemplo referirnos a las Propuestas abiertas del Grupo de Trabajo de Economía del 15m-Sol (http://madrid.tomalaplaza.net/2011/06/23/propuestas-abiertas-economia-sol/). 
cuál es esa "producción", en qué estructuras se da, a qué necesidades responde, qué recursos naturales utiliza. La cuestión es preguntarnos si queremos ligar esa reforma fiscal con: (1) la socialización de la responsabilidad de cuidados, con políticas de cuidados "clásicas" (la ley de dependencia y autonomía personal, las escuelas infantiles, derechos de "conciliación”...) y/o políticas innovadoras (¿comedores colectivos?); (2) la puesta en marcha de otro conjunto de mecanismos que permitan colectivizar los riesgos del vivir (sistemas de pensiones, con un debate sobre su carácter contributivo; recuperación de la noción de universalidad de los derechos...); y (3) recuperar estándares de calidad y universalidad de los sistemas educativos y sanitarios.

La pregunta es dónde poner a circular los recursos detraídos a la lógica de acumulación de capital: en qué estructuras, movidas por qué lógicas, con qué organización del trabajo y con qué formas de reconocer las necesidades. ¿Queremos una red de servicios públicos de carácter estatal?, ¿queremos otras formas de gestión de lo público más aterrizadas en lo local?, ¿queremos auto-gestión? Es un debate abierto. Para adentrarnos en él, debemos partir de la "economía diversa realmente existente” (León, 2009) y, sobre todo, de la diversidad posible. Pensando más allá de la díada mercado (lógica de acumulación)-estado (lógica de -supuesta- redistribución), hay que introducir un serio debate sobre el papel económico de los hogares: qué queremos que quede como su responsabilidad y qué tareas queremos externalizar. Y cómo democratizarlos, logrando una redistribución intra-hogar más justa de los trabajos y los recursos. Pero también hay que ir más allá de la tríada mercado-estado-hogares. Hay que introducir en el debate a la economía social y solidaria, la auto-gestión, las redes comunitarias y vecinales, la pequeña agricultura campesina, el tercer sector, etc. ¿Qué papel queremos que tenga cada forma posible? ¿Imaginamos nuevas maneras, por ejemplo, una forma de gestionar lo público que no caiga en la lógica burocrático-administrativa?

Todos estos son puntos que necesitamos discutir, entendiendo que esta discusión es política, y en ningún caso meramente técnica (los tecnicismos vendrán después, o ayudarán a que el debate sea informado, pero nunca suplantarán la política); y que ha de ser radicalmente democrática. Aquí aparece un problema fundamental: cómo hacerlo dada la carencia de estructuras políticas que posibiliten una democracia real. La crisis multidimensional tiene una faceta política clave, que pocas veces desde la economía feminista miramos de frente.

\section{VOLVIENDO A PENSAR LA ECONOMÍA DESDE LA POLÍTICA: EL 15M}

En este contexto de urgencia de debates éticos y políticos e inexistencia de estructuras de democracia real, no podemos terminar sin referirnos al movimiento 
$15 \mathrm{~m}^{33}$. Sin pretender hacer un análisis exhaustivo ni riguroso, sí merece la pena señalar varios elementos que apuntan a una potencia difícil de contener.

Primera potencia: El 15m ha vinculado, desde el primer momento, economía y política, partiendo de la enunciación de dos malestares de base: "lo llaman democracia y no lo es" y "vuestra crisis no la pagamos". Esto, lejos de ser el simple sumatorio de dos eslóganes, implica partir de la constatación de que las fallidas estructuras socioeconómicas van mano a mano de las fallidas estructuras políticas. El secuestro de estas por parte de las élites financieras, que se denunciaba desde el primer instante, se ha ido haciendo cada vez más evidente. Frente a esto, el 15m hace una crítica profunda del sistema socioeconómico y promueve alternativas, no desde la mirada de los expertos, sino desde la mirada crítica ciudadana; y, a la par, reinventa la política con la apuesta por el asamblearismo y la participación directa de la gente.

Segunda potencia: El 15m implica rebelarse contra los mecanismos que proliferan para controlar a la sociedad y que están en directa contradicción con la falta de supervisión de los grandes capitales. Gill y Roberts identifican esta asimetría como una de las características esenciales de lo que denominan el "neoliberalismo disciplinador" y afirman que "un sistema de mercado auto-regulado requiere la aplicación autoritaria y de gran alcance del poder estatal” (2001: 161). Si antes del 15m no había casi práctica política que se saliese de los cauces oficiales establecidos, el $15 \mathrm{~m}$ estalla esto, se apropia del espacio público y las calles; no se pide permiso para hacer una asamblea en una plaza, para cortar la calzada, para ocupar espacios vacíos donde realojar gente desahuciada. El 15m existe porque se rompe colectivamente con el miedo: "que no, que no tenemos miedo"; porque la amenaza de la exclusión no sirve para domesticar la precariedad: "juventud sin casa, sin curro, sin pensión: sin miedo”.

Tercera potencia: El 15m nace de un malestar común difuso que muestra cómo el conflicto capital-vida, lejos de ser una tensión teórica o abstracta, se encarna en la cotidianeidad, en las vidas concretas. Ese malestar generalizado expresa por tanto la afectación colectiva por un sistema en crisis. A la par, estamos presenciando un proceso de hipersegmentación social, en el que ciertos grupos van concentrando la "riqueza", mientras que la mayoría vive experiencias disímiles de intensificación de la precariedad en la vida o de paso de la precariedad a la exclusión. Una tarea clave es ir visibilizando y construyendo las raíces comunes de los problemas cotidianos, sin negar su desigual virulencia; ir dando nombre al malestar

33 Nos referimos al 15m porque este artículo está situado en el contexto del Estado español, pero en un sentido más amplio desearíamos abrir una reflexión sobre el conjunto del movimiento de indignación global en sus diversas versiones: las diversas revoluciones de la "Primavera árabe", el movimiento "occupy" (por ejemplo http://wearethe99percent.tumblr.com/); el movimiento "take the square" (http://takethesquare.net/), que no usa tanto el eslogan de "somos el 99\%". En el estado español se identifica con el $15 \mathrm{~m}$ (http://tomalaplaza.net/ 
común sin quedarnos atascadxs en visiones simplistas ("somos el 99\%", "los de abajo contra los de arriba”, "y las mujeres, peor”), ni atrapadxs en un "sálvese quien pueda". El reto es "escuchar y potenciar lo que hay en cada vida atomizada que consigue hacer resonar y vibrar lo común” (Gil, 2011: 314).

Cuarta potencia: El 15m ha llevado a la calle los cuerpos, con su vulnerabilidad, su precariedad y su finitud. Como afirma Butler refiriéndose a las manifestaciones en Egipto: "en el caso de las asambleas públicas, se ve claramente que no es sólo una lucha sobre el espacio público sino también sobre cuáles son las formas básicas en las que, como cuerpos, nos sostenemos en el mundo" (2011). En el mismo sentido, el $15 \mathrm{~m}$ ha roto las fronteras entre lo público y lo privado, especialmente durante el tiempo que duraron las acampadas. Comer, vestirse, bañarse, el cansancio, la sed, las quemaduras del sol... dejaban de ser cotidianeidades vividas de manera individualizada y oculta en lo doméstico para adueñarse del espacio público. Este derribo de fronteras macro/micro, público/privado ha continuado, por ejemplo, al ligar la paralización de desahucios con la crítica a la "economía del ladrillo”. El 15m muestra aquí dos capacidades cruciales: la conexión de las situaciones más privadas con los procesos públicos, el vínculo de la micropolítica con la macropolítica (la microeconomía con la macroeconomía); y la ruptura de la paz social, la expresión del conflicto de fondo, desde las esferas invisibilizadas del sistema socioeconómico; no desde el ámbito privilegiado del mercado, sino desde la cotidianeidad, la experiencia vivida en toda su amplitud.

Con todo lo anterior no queremos hacer una oda acrítica al $15 \mathrm{~m}$ ni pretender que no arrastra problemas ni contiene debilidades. Lo que queremos es insistir en cuatro cuestiones clave para responder a esa pregunta de qué hacer ante la crisis: necesitamos imperiosamente volver a poner la economía en manos de la política; identificar y rebelarnos frente a los mecanismos propios del neoliberalismo disciplinador; entender lo común como lugar no solo al que llegar, sino espacio del que partir; y encarnar los discursos reconstruyendo el nexo entre lo privado y lo público, lo personal y lo político, lo micro y lo macro, creando conflicto social desde los ámbitos invisibilizados de la vida.

En definitiva, estamos presenciando una grave crisis sistémica; se están produciendo profundos cambios en la vida cotidiana. Estas transformaciones van a ir ocurriendo con la suficiente parsimonia como para que vayamos normalizando las nuevas condiciones, llegando incluso a naturalizarlas. Como se afirma desde el ecologismo social, el cambio ya ha empezado y es imparable; la pregunta es si queremos gobernarlo, controlarlo democráticamente y con criterios de justicia, o si lo dejamos al libre arbitrio de los mercados. Esto exige encarar hondos debates políticos sobre los otros mundos posibles por los que apostar. Los feminismos, y la economía feminista en concreto, pueden realizar aportes cruciales en la confluencia de miradas críticas por la que apostábamos al comienzo de estas páginas; confluencia desde la que abrir debates radicalmente democráticos sobre qué es una vida que 
merece y cómo poner sus condiciones de posibilidad. Como rezaba un cartel en la marcha del 25J: "somos más y estamos mejor desorganizadas".

\section{BIBLIOGRAFÍA}

AGENJO CALDERÓN, Astrid (2011), Lecturas de la crisis en clave feminista: una comparación de la literatura en torno a los efectos específicos sobre las mujeres, "Papeles de Europa", 23, pp. 72-102 disponible en

http://revistas.ucm.es/index.php/PADE/article/view/37936/36702

AGUINAGA, Margarita (2010), Ecofeminismo: mujer y Pachamama, no solo es posible una crítica al capitalismo y al patriarcado, ViVe/ALAI, disponible en http://alainet.org/active/39531

ÁLVAREZ PERALTA, Nacho (2011), Vivir en el ajuste salarial permanente, "Diagonal periódico", núm. 146, disponible en

http://www.diagonalperiodico.net/Vivir-en-el-ajuste-salarial.html

ANTONOPOULOS, Rania (2009), Promoting gender equality through stimulus packages and public job creation. Lessons Learned from South Africa's Expanded, "The Levy Economics Institute of Bard College Public Policy Brief”, núm. 101, disponible en http://www.levyinstitute.org/pubs/ppb_101.pdf

BUTLER, Judith (2009), Marcos de Guerra. Las vidas lloradas, Barcelona, Buenos Aires, México, Paidós

BUTLER, Judith (2011), Bodies in Alliance and the Politics of the Street, “Transversal”, núm. 10/11, disponible en

http://www.eipcp.net/transversal/1011/butler/en

CARRASCO, Cristina (2009), Mujeres, sostenibilidad y deuda social, "Revista de Educación”, núm. Extraordinario, pp. 169-191, disponible en http://www.revistaeducacion.mec.es/re2009/re2009 08.pdf

CORNWALL, Richard R. (1998), A Primer on Queer Theory for Economists Interested in Social Identities, "Feminist Economics”, Vol. 4 núm. 2, págs. 73-82

DURÁN DE LAS HERAS, M ${ }^{\mathrm{a}}$ Ángeles (2011), El trabajo no remunerado en la economía global, Fundación BBVA.

ACOSTA. A. \& MARTÍNEZ, E. (eds.) (2009): El buen vivir: una vía para el desarrollo, Quito, Abya Yala

ESCOBAR, Arturo (2010), Latin America at a crossroads: Alternative modernizations, post-liberalism, or post-development?, “Cultural Studies”, 24:1, 1-65, disponible en http://www.sidint.net/docs/EscobarPaper.pdf

FERNÁNDEZ DURÁN, Ramón (1993), La explosión del desorden. La metrópoli como espacio de la crisis global, Fundamentos, disponible en www.herrera.unt.edu.ar/urbanismo2/primero/exdesorden.doc

GÁLVEZ, Lina y Juan TORRES (2009), La crisis económica y sus alternativas: una perspectiva de género, "Feminismo ante la crisis", Fórum de Política Feminista, pp. 15-30, disponible en http://www.forumpoliticafeminista.org/fotos/files/1.pdf

GIL, Silvia L. (2011a), Vidas precarias y la crisis global de la salud, "Diagonal periódico”, núm. 160-161, disponible en http://www.diagonalperiodico.net/Vidas-preca$\underline{\text { rias-y-la-crisis-global.html }}$ 
GIL, Silvia L. (2011b), Nuevos Feminismos. Sentidos comunes en la dispersión. Una historia de trayectorias y rupturas en el estado español, Madrid, Traficantes de Sueños, disponible en http://traficantes.net/index.php/content/download/28063/260518/file/mov 11_FINAL.pdf

GILL, Stephen y Adrienne ROBERTS (2011), Macroeconomic governance, gendered inequality, and global crises, B. Young, I. Bakker y D. Elson eds., "Questioning financial governance from a feminist perspective”, Routledge, pp. 155-70.HARAWAY, Donna (1991), Ciencia, cyborgs, mujeres: la reinvención de la naturaleza, Madrid, Valencia, Cátedra e Instituto de la Mujer D. L. (1995)

HERRERO, Yayo (2010a), Crisis ecológica. Aprendiendo a vivir pisando ligeramente sobre la tierra, Coordinadora estatal de Organizaciones Feministas coord., "Granada, treinta años después. Aquí y ahora. Jornadas Feministas Estatales”, disponible en http://www.feministas.org/IMG/pdf/crisis ecologica.pdf

HERRERO, Yayo (2010b), Cuidar: una práctica política anticapitalista y antipatriarcal, C. Taibo coord., "Decrecimientos: sobre lo que hay que cambiar en la vida cotidiana”, Los Libros de la catarata, pp. 17-31

INE (2011), Proyección de la Población de España a Corto Plazo 2011-2021, disponible en http://www.ine.es/prensa/np679.pdf

LATOUCHE, Serge (2008), La apuesta por el decrecimiento, Barcelona, Icaria.

LEÓN T., Magdalena (2009), Cambiar la economía para cambiar la vida, en A. Acosta y E. Martínez comps., "El buen vivir: una vía para el desarrollo”, AbyaYala, Quito, disponible en http://www.fedaeps.org/IMG/pdf/CAMBIAR_LA_ECONOMIA_PARA_CAMBIAR_LA_VIDA.pdf

MALO, Marta (2001), Feminización del trabajo, “Contrapoder”, 4-5, www.nodo50.org/cdc/fem-trabajo.htm

MEDIALDEA, Bibiana y ÁLVAREZ, Nacho (2005), Ajuste neoliberal y pobreza salarial: los 'working poor' en la Unión Europea, “Viento Sur”, núm. 82, pp. 56-64, disponible en http://www.ucm.es/info/epm/miembros/medialdea2005.pdf

MURILLO, Soledad (1996), El mito de la vida privada. De la entrega al tiempo propio, Madrid, Siglo XXI

NAREDO, José Manuel (2006), Raíces económicas del deterioro ecológico y social. Más allá de los dogmas, Madrid, Editorial Siglo XXI.

OCDE (2011), Divided We Stand: Why Inequality Keeps Rising, OECD.

PAIEWONSKY, Denise, Amaia PÉREZ OROZCO y Mar GARCÍA DOMÍNGUEZ (2008),

Cruzando Fronteras II. Migración y desarrollo desde una perspectiva de género, UNINSTRAW-Ministerio de Igualdad, disponible en http://www.remesasydesarrollo.org/uploads/media/Crossing BordersII WEB.pdf

PATEMAN, Carole (1988), El contrato sexual, Barcelona, México, Anthropos, Universidad Autónoma Metropolitana Iztapalapa (1995)

PÉREZ OROZCO, Amaia (2006a), Perspectivas feministas en torno a la economía: el caso de los cuidados, Consejo Económico y Social, Madrid, disponible en http://www.gemlac.org/recursos/amaia\%20perez\%20orozco 2006.pdf 
PÉREZ OROZCO, Amaia (2006b), Amenaza tormenta: la crisis de los cuidados y la reorganización del sistema económico, "Revista de economía crítica”, núm. 5, 737, disponible en

http://www.revistaeconomiacritica.org/sites/default/files/revistas/Revista Econom ia Critica 5.pdf

PICCHIO DEL MERCATO, Antonella (2001), Un enfoque macroeconómico 'ampliado' de las condiciones de vida, en C. Carrasco ed., "Tiempos, trabajos y géneros”, Barcelona, Universitat de Barcelona, págs. 15-37, disponible en http://www.paho.org/Spanish/HDP/hdw/chile-pi.PDF

PICCHIO DEL MERCATO, Antonella (2009), Condiciones de vida: Perspectivas, análisis económico y políticas públicas, "Revista de economía crítica”, núm. 7, pp. 27-54, disponible en

http://revistaeconomiacritica.org/sites/default/files/revistas/n7/2 condiciones de vida.pdf

BAKKER, I. \& GILL. S. (eds.) (2003): Power, Production and Social Reproduction, NY, Palgrave MacMillan.

PRECARIAS A LA DERIVA (2004), A la deriva por los circuitos de la precariedad femenina, Madrid, Traficantes de Sueños, disponible en

http://traficantes.net/index.php/content/download/18059/184955/file/precarias\%20a\%20la\%20deriva.pdf

YOUNG, B., BAKKER, I \& ELSON, D. (eds.) (2011): Questioning financial governance from a feminist perspective (2011), Routledge

QUIÉN DEBE A QUIÉN (2011), Vivir en deudocracia. Iban un portugués, un irlandés, un griego y un español... Barcelona, Icaria

Revista OBETS. Revista de Ciencias Sociales (2009), Núm. 4, Instituto Interuniversitario de Desarrollo Social y Paz, Universidad de Alicante, disponible en http://rua.ua.es/dspace/bitstream/10045/13396/6/Obets4.pdf

Revista OBETS. Revista de Ciencias Sociales (2011), Vol. 6 Núm. 1, Instituto Interuniversitario de Desarrollo Social y Paz, Universidad de Alicante, disponible en http://rua.ua.es/dspace/bitstream/10045/18071/1/OBETS 06 01.pdf

RIBAS-MATEOS, Natalia (2005), The Mediterranean in the age of globalization: migration, welfare \& borders, Transaction Publishers.

RÍO, Sira del (2003), La crisis de los cuidados: precariedad a flor de piel, "Rescoldos. Revista de Diálogo Social”, núm. 9, págs. 47-57, disponible en http://www.caesasociacion.org/feminismo/ficheros/la_crisis_de_los_cuidados.pdf

RÍO, Sira del y PÉREZ OROZCO, Amaia (2004): Una visión feminista de la precariedad desde los cuidados, "IX Jornadas de Economía Crítica", UCM, 25- 27 de marzo, disponible en www.ucm.es/info/economía/jec9/index.htm

SASSEN, Saskia (2008), Actores y espacios laborales de la globalización, "Papeles", núm. 1010, pp. 33-51, disponible en

http://biblioteca.hegoa.ehu.es/system/ebooks/17063/original/Actores y espacios laborales.pdf

MEDINA, J (2001): Suma Qamaña. La comprensión indígena de la Vida, La Paz, Comunicación PADEP/GTZ, disponible en

http://saludpublica.bvsp.org.bo/textocompleto/bvsp/boxp68/vida-buena.pdf

TAIBO, Carlos (2011), El decrecimiento explicado con sencillez, Catarata. 
TORTOSA, José María (2009), Sumak Kawsay, Suma Qamaña, Buen Vivir, Fundación Carolina, disponible en

ht t p : / / w w w. f und a c i o n c a r o l i n a.e s/e sES/nombrespropios/Documents/NPTortosa0908.pdf

VÁSCONEZ RODRÍGUEZ, Alison (2009), Precarious Work, Precarious Life: Interactions Between Paid and Unpaid Work for Women in Ecuador Before and during Recent Economic Crisis, "GEM IWG International Conference 2009", disponible en http://www.levyinstitute.org/pubs/GEMconf2009/presentations/Alison Vasconez R odriguez-Panel V.pdf

WEINGÄRTNER, Julia y Marta MONASTERIO MARTÍN (2010), Poner la vida en el centro: respuestas del ecofeminismo y del decrecimiento a la UE, disponible en http://www.ecologistasenaccion.org/article16371.html

YOUNG, Brigitte, Isabella BAKKER Y Diane ELSON (2011), Introduction, B. Young, I. Bakker y D. Elson eds., "Questioning financial governance from a feminist perspective”, Routledge, pp. 1-9 